\title{
Intervertebral disc penetration by antibiotics used prophylactically in spinal surgery: implications for the current standards and treatment of disc infections
}

\author{
Manu N. Capoor ${ }^{1,14}$ (D) Jan Lochman ${ }^{2} \cdot$ Andrew McDowell $^{3}$. Jonathan E. Schmitz Martin Solansky $^{2}$. \\ Martina Zapletalova ${ }^{2} \cdot$ Todd F. Alamin $^{5}$ - Michael F. Coscia ${ }^{6}$. Steven R. Garfin ${ }^{7} \cdot$ Radim Jancalek $^{8}$. Filip Ruzicka ${ }^{9}$. \\ A. Nick Shamie ${ }^{10} \cdot$ Martin Smrcka $^{11} \cdot$ Jeffrey C. Wang ${ }^{12} \cdot$ Christof Birkenmaier $^{13}$. Ondrej Slaby ${ }^{14}$
}

Received: 19 March 2018 / Accepted: 21 November 2018 / Published online: 1 December 2018

(c) The Author(s) 2018

\begin{abstract}
Purpose The presence of Propionibacterium acnes in a substantial component of resected disc specimens obtained from patients undergoing discectomy or microdiscectomy has led to the suggestion that this prominent human skin and oral commensal may exacerbate the pathology of degenerative disc disease. This hypothesis, therefore, raises the exciting possibility that antibiotics could play an important role in treating this debilitating condition. To date, however, little information about antibiotic penetration into the intervertebral disc is available.

Methods Intervertebral disc tissue obtained from 54 microdiscectomy patients given prophylactic cefazolin $(n=25)$, clindamycin $(n=17)$ or vancomycin ( $n=12)$ was assayed by high-performance liquid chromatography, with cefaclor as an internal standard, to determine the concentration of antibiotic penetrating into the disc tissue.

Results Intervertebral disc tissues from patients receiving the positively charged antibiotic clindamycin contained a significantly greater percentage of the antibacterial dose than the tissue from patients receiving negatively charged cefazolin $(P<0.0001)$ and vancomycin, which has a slight positive charge $(P<0.0001)$.

Conclusion Positively charged antibiotics appear more appropriate for future studies investigating potential options for the treatment of low-virulence disc infections.
\end{abstract}

Graphical abstract These slides can be retrieved under Electronic Supplementary Material.
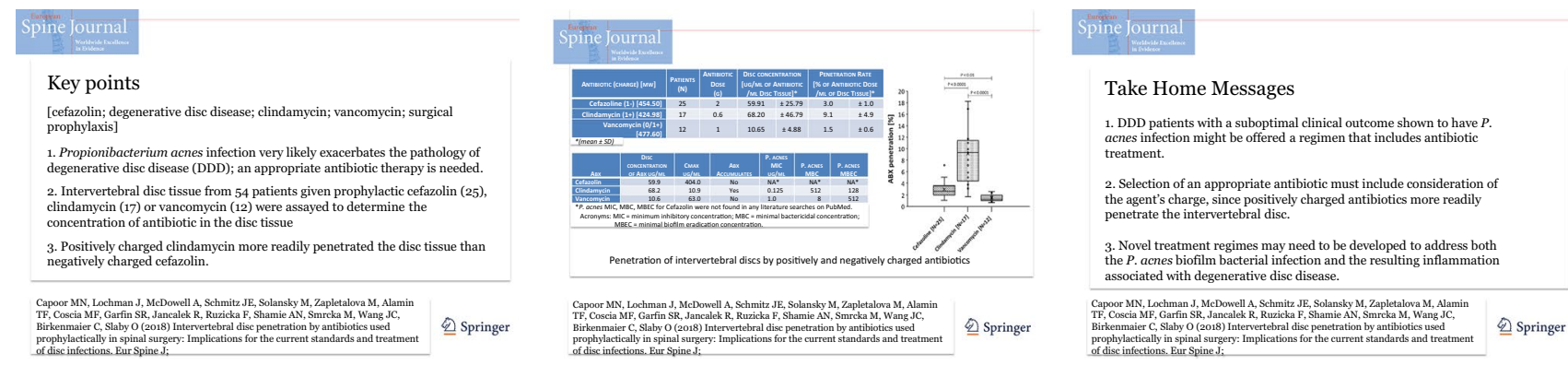

Keywords Propionibacterium acnes $\cdot$ Cutibacterium acnes $\cdot$ Degenerative disc disease $\cdot$ Biofilm $\cdot$ Cefazolin . Clindamycin $\cdot$ Vancomycin $\cdot$ Surgical prophylaxis

Electronic supplementary material The online version of this article (https://doi.org/10.1007/s00586-018-5838-z) contains supplementary material, which is available to authorized users.

Extended author information available on the last page of the article 


\section{Introduction}

Spine-related degeneration and symptomatology is a leading cause of disability worldwide, and efforts to prevent or retard this degeneration would potentially have a significant effect on the global population [1-3]. Well-described explanations for disc degeneration include genetic predisposition, biomechanical factors, changes of the disc architecture during the ageing process, trauma and exogenous factors such as smoking. Many of these risk factors are unfortunately not reversible, and treatment algorithms for the prevention of disc degeneration would not be practical. However, the identification of potentially reversible factors that can affect the degenerative process may represent new tangible treatment strategies [4].

Propionibacterium acnes (P. acnes) is a Gram-positive, aerotolerant anaerobic species prevalent in the sebaceous gland-rich areas of the human skin [5,6]. As a ubiquitous slow-growing organism with the capacity to form biofilm under in vitro and in vivo conditions $[7,8], P$. acnes has been implicated in a number of opportunistic infections, particularly delayed post-operative device-related infections [9]; these commonly include prosthetic shoulder joint [10], cerebrovascular [11], breast [12] and cardiovascular device implants [13].

In 2001, Stirling et al. [14] first published evidence suggesting a relationship between chronic bacterial infection of the disc and sciatica. In 2015, two meta-analyses reported a pooled prevalence of bacteria at 34\% [15] and $36.2 \%$ [16], with P. acnes as the predominant species. Furthermore, recent studies by Capoor et al. [17] and OhrtNissen et al. [18], utilizing fluorescence in situ hybridization coupled with confocal laser scanning microscopy (FISH-CLSM), directly visualized P. acnes as biofilm within surgically removed intervertebral disc tissue; such findings are practically impossible to explain by contamination as this would require the contaminant to form a biofilm deep within a retrieved tissue fragment during the brief time between exposure, removal and freezing.

In contrast, several studies have reported very little or no $P$. acnes in samples from patients with lumbar disc herniation, dismissing results where positive associations were found as likely contamination from the patient's skin, surgical environment or the laboratory environment [19-21]. In most of these studies, however, retrieved disc material did not undergo a critical biofilm disassembly step before enrichment culture, which is imperative to maximize detection and reduce the possibility of a falsenegative result $[17,18]$. This can be achieved by homogenization with a mortar and pestle or Stomacher ${ }^{\circledR} 80$, with the option of a short sonication step. The process of disrupting $P$. acnes biofilm is a recognized approach to maximize the detection of $P$. acnes organisms associated with other infections, notably those associated with prosthetic joints [22].

When evaluating ways to address the role of $P$. acnes infection of the intervertebral disc and the subsequent pathology, the use of appropriate antibiotics must be considered. In principle, this same approach also needs to be applied to perioperative antibiotic prophylaxis. Administration of an antibiotic aims to protect not only against $P$. acnes in the context of intervertebral disc surgery, but also against other opportunistic pathogens that exist on and in the host skin, and possibly within the anatomical region of interest as well as the environment of the operating room. Walters et al. [23] have indicated that, when identifying a particular antibiotic to be used for treatment of the intervertebral disc, several factors need to be taken into account in regard to penetration of the disc and characteristics of the drug. Such factors include molecular charge, degree of disc degeneration and disc size. The intervertebral disc contains an extensive extracellular matrix maintained by the nucleus pulposus (NP) and annulus fibrosus cells, which together occupy less than $0.5 \%$ of the tissue volume [24]. The major proteoglycan of the intervertebral disc is aggrecan, which consists of a core protein containing up to 100 covalently bound keratin and chondroitin sulphate molecules. These highly negatively charged glycosaminoglycans (GAGs) absorb water and confer a viscoelastic behaviour to the tissue, in particular to the highly hydrated NP [25].

The American Society of Health-System Pharmacists' and the North American Spine Society's guidelines regarding surgical prophylaxis suggest the use of cefazolin, a negatively charged antibiotic, for spinal procedures. However, clindamycin, vancomycin and gentamicin (positively charged antibiotics) are common alternatives under specific circumstances (such as an allergy against cephalosporins or beta-lactams) and may also be used for surgical prophylaxis [26, 27]. Cefazolin is the first-line prophylactic antibiotic recommended for patients undergoing spinal surgery in the USA. If a patient has an anaphylactic penicillin allergy or is specifically allergic to cephalosporins, then clindamycin is typically the second-line medication. Vancomycin is reserved for methicillin-resistant Staphylococcus aureus (MRSA) carriers, or suspected MRSA-infected patients, or if the patient is also allergic to clindamycin. Gentamicin is seen as primarily targeting Gram-negative entities and is not generally used as a prophylactic antibiotic given its relatively higher risk profile. Although vancomycin is an excellent antibiotic, there is pressure to use it only when absolutely necessary, in part to minimize the risk of resistance development, but also in response to its higher risk profile compared with cefazolin.

Since the internal components of the disc are negatively charged, antibiotics such as cefazolin, which are 
also negatively charged, will have difficulty penetrating the disc. Das et al. [28] have indicated the size of an antibiotic molecule will also influence the ease of diffusion and that molecules possessing molecular weights $<10 \mathrm{kDa}$ should be able to dissipate more quickly and reach a larger area of the disc than bigger molecules. The concentration of such small molecules (antibiotics such as cefazolin are $\sim 0.5 \mathrm{kDa}$ ) does, however, dissipate quickly, and the effects of the drug may not be as prolonged once serum levels begin to drop after a single administration [29]. Other characteristics of an antibiotic that may influence its diffusion are its lipophilicity and hydrophilicity, as well as its degree of bonding to plasma proteins. Other variables to note in this context would be the rate of renal excretion at first pass and possibly the condition of the endplate and whether it is normal, sclerotic or inflamed.

Against such a background, and to aid practitioners treating disc infections, this study details a much needed comparative analysis of intervertebral disc penetration by three antibiotics used prophylactically in spine surgery.

\section{Materials and methods}

\section{Biological samples}

Disc material for this current project ( $n=54$ patient) was obtained from the previously described Capoor et al. [17] and Capoor et al. [30] studies; this subset of disc material had not been processed in these earlier studies and, therefore, remained available for analysis. These studies were approved by the Institutional Review Boards of St. Anne's University Hospital (Brno, Czech Republic) and University Hospital Brno (Brno, Czech Republic), and written informed consent was obtained from each patient. Of the 54 patients, 25 were treated with cefazolin $(2 \mathrm{~g}), 17$ with clindamycin $(0.6 \mathrm{~g})$, and 12 with vancomycin $(1 \mathrm{~g})$. Cefazolin was the first-line antibiotic used for surgical prophylaxis. Patients allergic to cephalosporins were given intravenous clindamycin, and patients allergic to both cephalosporins and clindamycin received vancomycin. Prophylactic antibiotics were administered intravenously as a single dose prior to incision (on average, slightly more than half an hour prior to skin incision and under $1 \mathrm{~h}$ prior to excision of disc tissue).

\section{Quantitative analysis of vancomycin, cefazolin and clindamycin in disc tissue specimens}

Frozen $\left(-80^{\circ} \mathrm{C}\right)$ disc tissue specimens $(50-100 \mathrm{mg})$ were placed into a 2-ml Potter-Elvehjem tissue homogenizer along with $250 \mu \mathrm{l}$ of grinding buffer $\left(25 \mathrm{mM} \mathrm{KH}_{2} \mathrm{PO}_{4}, \mathrm{pH}\right.$ 3) containing cefaclor as an internal standard (final concentration of $10 \mu \mathrm{g} / \mathrm{ml}$ ). The mixture was then processed twice for $1 \mathrm{~min}$ at room temperature, and the resulting suspensions sonicated for $10 \mathrm{~min}$ in a sonicator bath (Branson $5510)$ at room temperature. Samples were then centrifuged at $16.000 \times g$ for $30 \mathrm{~min}$ at $4{ }^{\circ} \mathrm{C}$. Supernatants were filtered through Ultrafree-MC microcentrifuge filters $(0.22 \mu \mathrm{m}$, Sigma M9785) and transferred into vials for high-performance liquid chromatography (HPLC) analysis. Detection of antibiotics in samples was done as previously described [29]. In brief, the HPLC analysis was performed on an Agilent Technologies 1100 system with diode-array detection. Chromatographic separation was performed on Ascentis ${ }^{\circledR}$ Express C18 column $(15 \mathrm{~cm} \times 4.6 \mathrm{~mm}, 2.7 \mu \mathrm{M}$, Supelco $)$ through the binary gradient (phase $\mathrm{A}, 25 \mathrm{mM} \mathrm{KH}_{2} \mathrm{PO}_{4}$, $\mathrm{pH}$ 3 ; phase $\mathrm{B}$, acetonitrile) at a flow rate of $0.9 \mathrm{ml} / \mathrm{min}$ and detected at 204 (clindamycin) and $270 \mathrm{~nm}$ (vancomycin, cefaclor and cefazolin).

\section{Antibiotic assays}

The concentrations of cefazolin, clindamycin and vancomycin were determined using HPLC. Antibiotic concentrations were calculated by comparing the peak areas of the respective antibiotic with that of the internal cefaclor standard, using a standard chromatogram containing known concentrations of all of the antibiotics along with the internal standard.

\section{Statistical analysis}

Antibiotic concentrations are presented as mean values ( \pm standard deviation). Differences were analysed using Student's $t$ test, and differences resulting in a $p$ value $\leq 0.001$ were considered statistically significant.

\section{Results}

Representative chromatograms from the HPLC analysis of resected disc tissues are presented in Fig. 1. Peaks corresponding to the antibiotics cefazolin, clindamycin and vancomycin were well resolved and separated from the internal standard cefaclor. Calibration curves were constructed for the analytes, and the assays validated for limit of quantitation (LOQ) and precision. The linearity of the methods was excellent with correlation coefficients $(r)$ greater than 0.99 for all antibiotics and LOQ that ranged from 0.5 to $2.0 \mu \mathrm{g} / \mathrm{ml}$ (Supplementary Table 1). Precision as determined by the relative standard deviation for disc tissue sample containing cefazolin $(n=3)$ was $8.6 \%$. Comparison of the antibiotic peak areas with those of cefaclor enabled calculation of the concentration of each antibiotic in the resected disc tissue. In several samples, compounds with retention times close to that of vancomycin were detected. 

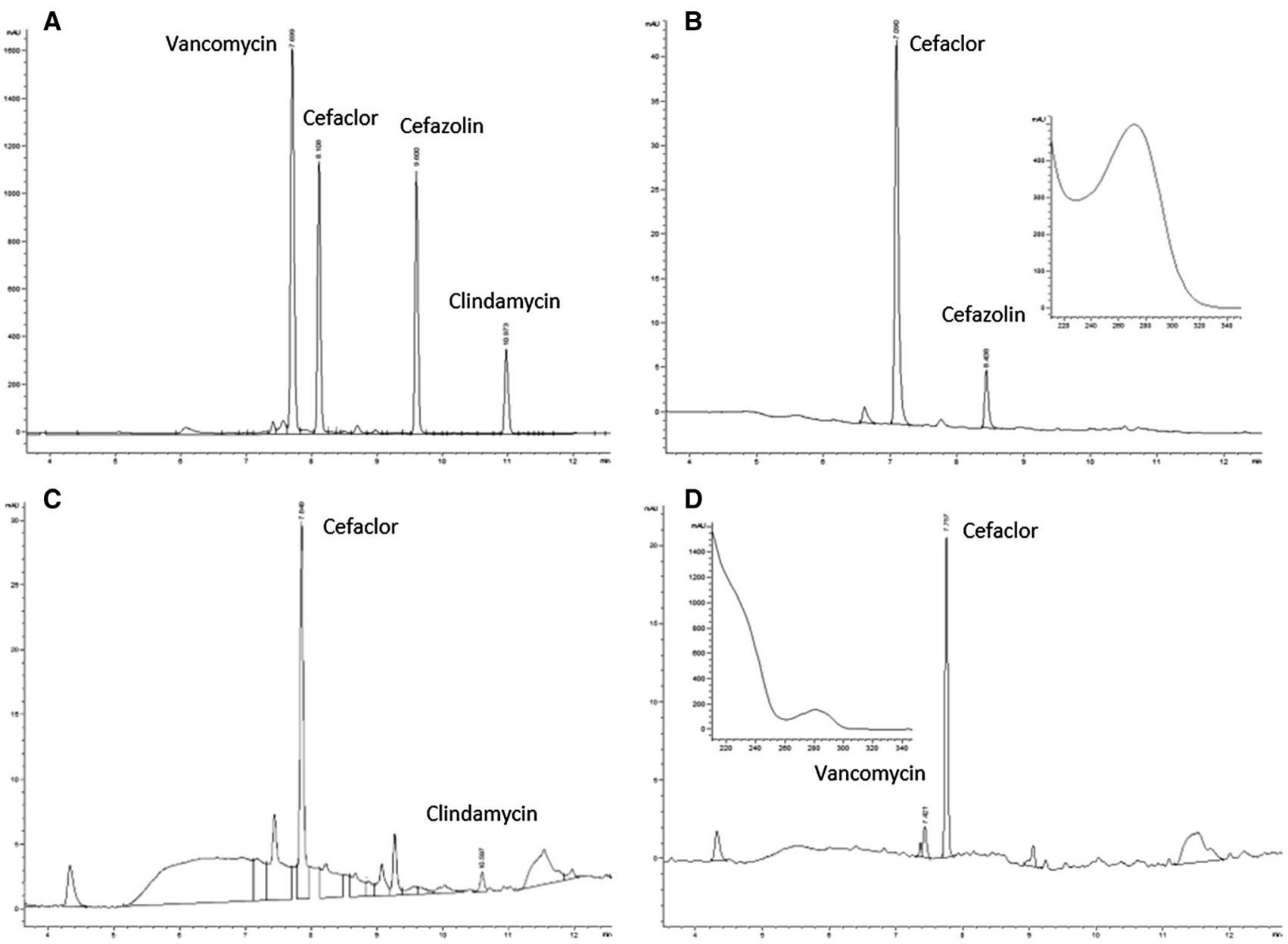

Fig. 1 Determination of tested antibiotics on C18 column by HPLC. Chromatogram of mixed standards at $204 \mathrm{~nm}$ (a), chromatogram of representative disc tissue specimen with cefazolin with its spectrum

detected at $270 \mathrm{~nm}(\mathbf{b})$, clindamycin detected at $204 \mathrm{~nm}$ (c) and vancomycin with its spectrum detected at $204 \mathrm{~nm}$ (d)

In these samples, we validated the correct quantification of vancomycin through spectral analysis. The data are collated in Table 1. The concentrations of cefazolin and clindamycin in the NP were similar, although the clindamycin concentration was significantly higher in proportion to the intravenously administered amount (in milligrams).

The concentration of vancomycin in the NP was higher than those of cefazolin and clindamycin, and it was also a higher percentage of the antibiotic dose. The penetration proportion data are presented graphically in Fig. 2. It is clear from these data that the positively charged antibiotic clindamycin penetrates the disc much more efficiently than the negatively charged cefazolin.

Table 1 Penetration of intervertebral disc tissue by antibiotics

\begin{tabular}{|c|c|c|c|c|c|c|}
\hline \multirow{2}{*}{$\begin{array}{l}\text { Antibiotic (charge) (mw) } \\
\text { Cefazolin (1-) [454.50] }\end{array}$} & \multirow{2}{*}{$\begin{array}{l}\text { Patients }(N) \\
\\
25\end{array}$} & \multirow{2}{*}{$\begin{array}{l}\text { Antibiotic } \\
\text { dose }(\mathrm{g}) \\
2\end{array}$} & \multicolumn{2}{|c|}{$\begin{array}{l}\text { Disc concentration } \\
\text { ( } \mathrm{ug} / \mathrm{ml} \text { of antibiotic/ml } \\
\text { disc tissue) })^{\mathrm{a}}\end{array}$} & \multicolumn{2}{|c|}{$\begin{array}{l}\text { Penetration } \\
\text { rate }(\% \text { of } \\
\text { antibiotic } \\
\text { dose } / \mathrm{ml} \text { of } \\
\text { disc tissue) }\end{array}$} \\
\hline & & & 59.91 & \pm 25.79 & 3.0 & \pm 1.0 \\
\hline Clindamycin $(1+)$ [424.98] & 17 & 0.6 & 68.20 & \pm 46.79 & 9.1 & \pm 4.9 \\
\hline Vancomycin $(0 / 1+)$ [477.60] & 12 & 1 & 10.65 & \pm 4.88 & 1.5 & \pm 0.6 \\
\hline
\end{tabular}

$\mathrm{a}(\mathrm{mean} \pm \mathrm{SD})$ 


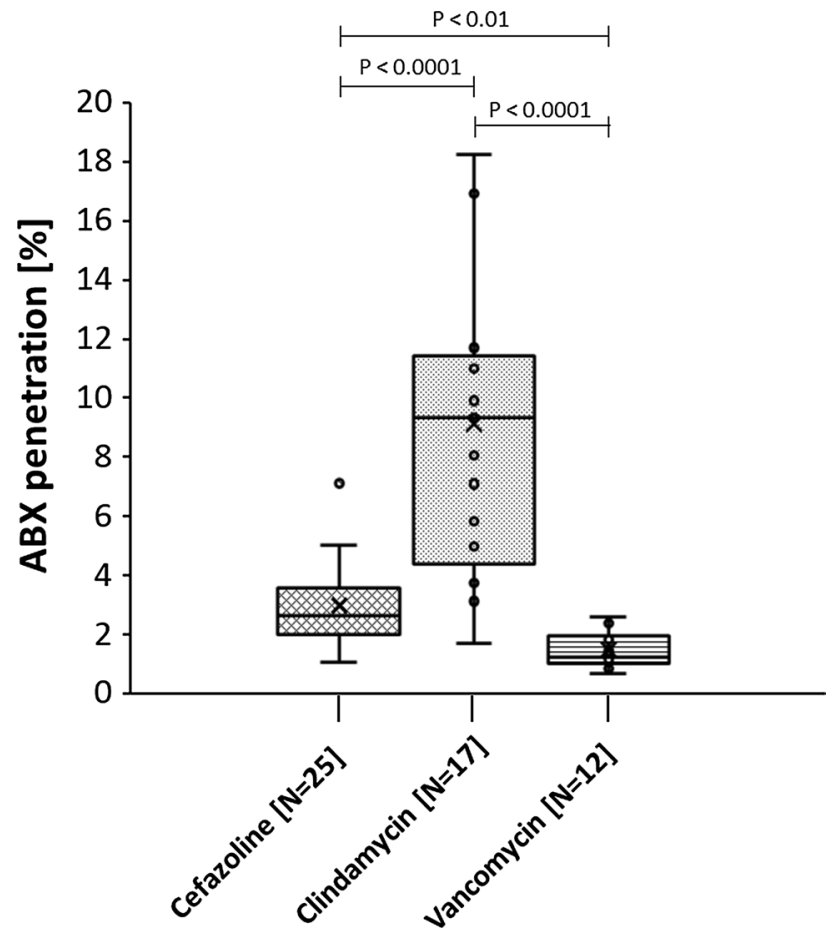

Fig. 2 Penetration of intervertebral discs by antibiotics. Data are summarized in Table 1

\section{Discussion}

Our study has the inherent limitation of not being a randomized, controlled trial where different antibiotics are randomly assigned to different individuals and where equal group sizes can be achieved. It is obvious, however, that such a study would never receive ethics approval in times where the effectiveness of perioperative antibiotics in spine surgery is established and guidelines as to the choice of antibiotic exist. On the other hand, the patients included in this study are representative of the typical patients undergoing intervertebral disc surgery.

From a clinician's point of view the consensus that degenerative disc disease is predominantly a biomechanical phenomenon, which can be fully addressed by mechanical interventions, is dissipating. This recognition follows the long-standing frustration in connection with surgical treatment for disc degeneration and the associated side effects. These procedures have never been as successful as projected and result in greater-than-expected poor outcomes for discectomies and fusions performed for low back pain without instability or other obvious anatomical explanations. In particular, the bio-psycho-social aspects of chronic low back pain (CLBP) are well established. But as new research details the presence, prevalence and consequences of lowgrade bacterial infection of degenerate human discs, an expansion of our understanding is taking place similar to that seen with radiculopathy associated with lumbar disc herniation. While the mechanical compression of an affected nerve root was originally seen as the only pathological mechanism of lumbar radiculopathy, subsequent research demonstrated that degenerative disc tissue contains several pro-inflammatory cytokines that are extremely irritating to the dorsal root ganglion. Notwithstanding a key role for biomechanics in DDD, and many associated degenerative conditions of the spine, it is increasingly recognized that biomechanics alone is not the only relevant factor. DDD-associated bio-psychosocial issues are one major aspect of this complex disease, but covert, low-grade disc infections may prove to be another important aetiologic cause. If true, this may ultimately place us in a better position to successfully treat DDD or prevent suboptimal outcomes post-surgery.

A key point is whether physicians should treat DDD with prolonged high-dose antibiotic regimens when no evidence of infection is present. In an era of growing antibiotic resistance, we most definitively recommend against such an indiscriminate approach; the effect of long-term antibiotic usage on the normal host microbiota, especially within the gut, is also a concern given the importance of its composition in health and disease. A much more pragmatic approach would be to routinely screen surgically removed disc material for the presence or absence of underlying infection, primarily that caused by $P$. acnes due to its association with disc disease and low back pain [31]. The use of an appropriate diagnostic test with appropriate sensitivity and specificity would enable an evidenced-based and informed approach to treatment; for example, patients with suboptimal clinical outcomes after an index surgery and evidence of bacterial biofilm in their samples might be offered a regimen that also includes antibiotic treatment. Indeed, once we realize that the intervertebral disc with its lack of vascularity and its low oxygen tension/low $\mathrm{pH}$ is vulnerable to infection, and behaves much like an implant or like a devitalized bone sequester, it could be argued that routine analysis of samples for occult infection is essential.

If antibiotic therapy is indicated, an appropriate antibiotic must be selected. Before surgical procedures, prophylactic antibiotics are routinely given to patients to prevent postsurgical infections. In the case of spinal surgery patients, investigation of how these antibiotics penetrate the disc tissue not only provides valuable information on their potential effectiveness in this context, but more generally their potential suitability for treating underlying disc infections post-surgery or in non-surgical patients when spontaneous discitis is suspected. In this study, therefore, we examined the relative effectiveness of the positively charged antibiotics clindamycin and vancomycin, together with the negatively charged antibiotic cefazolin, at penetrating disc tissue amongst patients who had undergone spinal surgery; these antibiotics were used based on recommended guidelines. 
Table 2 Disc antibiotic concentrations and MIC, MBC and MBEC values for P. acnes

\begin{tabular}{lllllll}
\hline Antibiotic & $\begin{array}{l}\text { Disc concen- } \\
\text { tration }\end{array}$ & CMAX & $\begin{array}{l}\text { Antibiotic accu- } \\
\text { mulates }\end{array}$ & MIC $^{\mathrm{a}}$ & $\mathrm{MBC}^{\mathrm{a}}$ & $\mathrm{MBEC}^{\mathrm{a}}$ \\
\hline Cefazolin & 59.9 & $404.0[40]$ & No & $\mathrm{NA}^{\mathrm{b}}$ & $\mathrm{NA}^{\mathrm{b}}$ & $\mathrm{NA}^{\mathrm{b}}$ \\
Clindamycin & 68.2 & $10.9[41]$ & Yes & 0.125 & 512 & 128 \\
Vancomycin & 10.6 & $63.0[42]$ & No & 1.0 & 8 & 512 \\
\hline
\end{tabular}

$C M A X$ maximum serum concentration, $M I C$ minimum inhibitory concentration, $M B C$ minimal bactericidal concentration, $M B E C$ minimal biofilm eradication concentration. Note: all values are in $\mu \mathrm{g} / \mathrm{ml}$

${ }^{a} P$. acnes $\mathrm{MIC}, \mathrm{MBC}, \mathrm{MBEC}$ reference values from [39]

${ }^{\mathrm{b}}$ P. acnes MIC, MBC, MBEC for cefazolin were not found in any literature searches on PubMed
The positively charged antibiotic clindamycin appeared to penetrate intervertebral discs much more efficiently than the negatively charged antibiotic cefazolin. This result is consistent with that of a recent study suggesting charge has a significant effect on the kinetics of antibiotic penetration into the intervertebral disc [32], and earlier studies, which demonstrated the superior intervertebral disc penetration of positively charged gentamicin over the negatively charged antibiotics cefuroxime [33] or cefazolin [34]. Indeed, it is possible that we are still underestimating the final concentration of clindamycin in the disc tissue if a proportion is still remaining bound to the negatively charged internal components of the disc material during processing and therefore, is not released into the supernatant for testing. On the other hand, vancomycin, which has a slight positive charge, was even less efficient than the negatively charged antibiotic cefazolin at penetrating the intervertebral disc. This may reflect its relatively high molecular weight (1449.3) compared to other positively charged antibiotics like clindamycin (425.0) or gentamicin (477.6), as well as other factors that hinder disc penetration [35]. Interestingly, diffusion of the uncharged antibiotic linezolid into the annulus fibrosus, NP and vertebral bone of rabbits was found to be the same or, in the case of the annulus fibrosus, poorer than that of vancomycin [36]. A relatively new glycopeptide antibiotic, dalbavancin, may offer an advantage over vancomycin, as once-weekly dalbavancin appears as effective as daily vancomycin for the treatment of acute bacterial skin and skin structure infections [37].

One limitation of our study is that the time taken between antibiotic administration and nucleus fragment extraction was not always identical between individuals. This simply reflects the dynamic environment of the surgical setting which makes precise timings of procedures extremely difficult, even with highly experienced spinal surgeons as used in our study. So, in the series presented here, the time between antibiotic administration and specimen extraction varied slightly in the range of between 40 and $60 \mathrm{~min}$. This introduces a certain inhomogeneity with regard to the individual pharmacodynamics, but it represents the best possible approximation.
Antibiotic selection and action is also complicated by the observation that $P$. acnes can form biofilm within intervertebral disc specimens and on titanium surfaces used in spinal instrumentation [17]. Bacterial biofilms protect organisms from the immune system and antibiotics, thus promoting the persistence of chronic infections that are difficult to eradicate. Although bacteria grow in nature as a biofilm, it is noteworthy that most antimicrobial testing for acute (high-virulence) infections does not take this into account; this is especially relevant to our study since $P$. acnes biofilm has been demonstrated within the intervertebral disc [17, 18]. As a consequence, it is important to understand how the concentrations of antibiotics within disc tissue relate to not only minimum inhibitory concentration (MIC) values for $P$. acnes, but critically minimal biofilm eradication concentration (MBEC) values as well. Review of the scientific literature identified two key papers where MIC, MBEC and minimum bactericidal concentration (MBC) values for clindamycin and vancomycin versus $P$. acnes were summated from multiple English-language studies (Table 2) [38, 39]. We could not, however, find any data for cefazolin in the literature despite its use as a first-line prophylactic antibiotic by orthopaedic surgeons. While the concentrations of clindamycin and vancomycin assayed within the disc tissue were found to be well above MIC values, they fell well below reported MBEC values (Table 2). In the case of clindamycin, however, the disc concentration of the antibiotic was able to accumulate approximately half (e.g. $68.2 \mu \mathrm{g} / \mathrm{ml}$ ) of the necessary MBEC value (e.g. $128 \mu \mathrm{g} / \mathrm{ml}$ ) after a single dose, whereas vancomycin's disc concentration $(10.6 \mu \mathrm{g} / \mathrm{ml})$ was still significantly short of its MBEC value of 512 (Table 2); it would be expected, of course, that given multiple doses, accumulated levels of antibiotic may ultimately reach the designated MBC and MBEC values.

While acknowledging the relatively small size of our dataset, the results from our study suggest that cefazolin may not be an optimal choice for standard perioperative prophylaxis in spinal surgery involving the intervertebral discs, and other alternatives should be considered and investigated. Similarly, a weight-based dosing of both clindamycin and vancomycin, rather than uniform dosing utilized in 
these patients, could also be beneficial. The comparatively poor penetration of cefazolin into human discs could result in an inferior prophylactic suppression of clinically silent reservoirs of $P$. acnes. If present, $P$. acnes from such discs could then be spread and propagated during surgery leading to failed fusions, as some authors have reported, or to otherwise inferior clinical outcomes. Furthermore, cefazolin is not the most effective antibiotic agent against $P$. acnes and most types of Staphylococcus epidermidis and many $S$. aureus strains, the latter ones being responsible for a majority of pyogenic surgical site infections.

In conclusion, our study data add support to the idea that spinal surgery involving the intervertebral discs may require dedicated perioperative antibiotic regimens that differ from the "cefazolin standard".

Acknowledgements We express deep thanks to Professor Vincent A. Fischetti of Rockefeller University, John Baird and Fahad Ahmed for their significant insights.

Funding DiscitisDx, Inc., provided support in the form of a research grant. Neither DiscitisDx, Inc., nor any other commercial organization provided any support in the form of salaries for authors and did not have any role in the study design, data collection and analysis, decision to publish, or preparation of the manuscript.

\section{Compliance with ethical standards}

Conflict of interest MNC, OS, JES, FR, RJ, MS and CB have stock ownership or options in DiscitisDx, Inc. MNC and OS have filed several patent applications, which have been assigned to DiscitisDx, Inc.

Open Access This article is distributed under the terms of the Creative Commons Attribution 4.0 International License (http://creativeco mmons.org/licenses/by/4.0/), which permits unrestricted use, distribution, and reproduction in any medium, provided you give appropriate credit to the original author(s) and the source, provide a link to the Creative Commons license, and indicate if changes were made.

\section{References}

1. Nahin RL (2015) Estimates of pain prevalence and severity in adults: United States, 2012. J Pain 16:769-780. https://doi. org/10.1016/j.jpain.2015.05.002

2. Neuhauser H, Ellert U, Ziese T (2005) Chronic back pain in the general population in Germany 2002/2003: prevalence and highly affected population groups. Gesundheitswesen 67:685693. https://doi.org/10.1055/s-2005-858701

3. Bjorck-van Dijken C, Fjellman-Wiklund A, Hildingsson C (2008) Low back pain, lifestyle factors and physical activity: a population based-study. J Rehabil Med 40:864-869. https://doi. org/10.2340/16501977-0273

4. Lin Y, Jiao Y, Yuan Y, Zhou Z, Zheng Y, Xiao J, Li C, Chen Z, Cao P (2018) Propionibacterium acnes induces intervertebral disc degeneration by promoting nucleus pulposus cell apoptosis via the TLR2/JNK/mitochondrial-mediated pathway. Emerg Microbes Infect 7:1. https://doi.org/10.1038/s41426-017-0002-0
5. Jahns AC, Eilers H, Alexeyev OA (2016) Transcriptomic analysis of Propionibacterium acnes biofilms in vitro. Anaerobe 42:111-118. https://doi.org/10.1016/j.anaerobe.2016.10.001

6. Lee MJ, Pottinger PS, Butler-Wu S, Bumgarner RE, Russ SM, Matsen FA 3rd (2014) Propionibacterium persists in the skin despite standard surgical preparation. J Bone Joint Surg Am 96:1447-1450. https://doi.org/10.2106/JBJS.M.01474

7. Perry A, Lambert P (2011) Propionibacterium acnes: infection beyond the skin. Expert Rev Anti Infect Ther 9:1149-1156. https ://doi.org/10.1586/eri.11.137

8. Bayston R, Ashraf W, Barker-Davies R, Tucker E, Clement R, Clayton J, Freeman BJ, Nuradeen B (2007) Biofilm formation by Propionibacterium acnes on biomaterials in vitro and in vivo: impact on diagnosis and treatment. J Biomed Mater Res A 81:705-709. https://doi.org/10.1002/jbm.a.31145

9. Portillo ME, Corvec S, Borens O, Trampuz A (2013) Propionibacterium acnes: an underestimated pathogen in implantassociated infections. Biomed Res Int 2013:804391. https://doi. org/10.1155/2013/804391

10. Singh JA, Sperling JW, Schleck C, Harmsen W, Cofield RH (2012) Periprosthetic infections after shoulder hemiarthroplasty. J Shoulder Elbow Surg 21:1304-1309. https://doi.org/10.1016/j. jse.2011.08.067

11. Conen A, Walti LN, Merlo A, Fluckiger U, Battegay M, Trampuz A (2008) Characteristics and treatment outcome of cerebrospinal fluid shunt-associated infections in adults: a retrospective analysis over an 11-year period. Clin Infect Dis 47:73-82. https://doi. org $/ 10.1086 / 588298$

12. Rieger UM, Pierer G, Luscher NJ, Trampuz A (2009) Sonication of removed breast implants for improved detection of subclinical infection. Aesthet Plast Surg 33:404-408. https://doi.org/10.1007/ s00266-009-9333-0

13. Rohacek M, Weisser M, Kobza R, Schoenenberger AW, Pfyffer GE, Frei R, Erne P, Trampuz A (2010) Bacterial colonization and infection of electrophysiological cardiac devices detected with sonication and swab culture. Circulation 121:1691-1697. https:// doi.org/10.1161/CIRCULATIONAHA.109.906461

14. Stirling A, Worthington T, Rafiq M, Lambert PA, Elliott TS (2001) Association between sciatica and Propionibacterium acnes. Lancet 357:2024-2025. https://doi.org/10.1016/S0140 $-6736(00) 05109-6$

15. Urquhart DM, Zheng Y, Cheng AC, Rosenfeld JV, Chan P, Liew S, Hussain SM, Cicuttini FM (2015) Could low grade bacterial infection contribute to low back pain? A systematic review. BMC Med 13:13. https://doi.org/10.1186/s12916-015-0267-x

16. Ganko R, Rao PJ, Phan K, Mobbs RJ (2015) Can bacterial infection by low virulent organisms be a plausible cause for symptomatic disc degeneration? A systematic review. Spine (Phila Pa 1976) 40:E587-E592. https://doi.org/10.1097/brs.0000000000 000832

17. Capoor MN, Ruzicka F, Schmitz JE, James GA, Machackova T, Jancalek R, Smrcka M, Lipina R, Ahmed FS, Alamin TF, Anand N, Baird JC, Bhatia N, Demir-Deviren S, Eastlack RK, Fisher S, Garfin SR, Gogia JS, Gokaslan ZL, Kuo CC, Lee YP, Mavrommatis K, Michu E, Noskova H, Raz A, Sana J, Shamie AN, Stewart PS, Stonemetz JL, Wang JC, Witham TF, Coscia MF, Birkenmaier C, Fischetti VA, Slaby O (2017) Propionibacterium acnes biofilm is present in intervertebral discs of patients undergoing microdiscectomy. PLoS ONE 12:e0174518. https://doi.org/10.1371/journ al.pone. 0174518

18. Ohrt-Nissen S, Fritz BG, Walbom J, Kragh KN, Bjarnsholt T, Dahl B, Manniche C (2018) Bacterial biofilms: a possible mechanism for chronic infection in patients with lumbar disc herniation-a prospective proof-of-concept study using fluorescence in situ hybridization. APMIS 126:440-447. https://doi. org/10.1111/apm. 12841 
19. Ben-Galim P, Rand N, Giladi M, Schwartz D, Ashkenazi E, Millgram M, Dekel S, Floman Y (2006) Association between sciatica and microbial infection: true infection or culture contamination? Spine (Phila Pa 1976) 31:2507-2509. https://doi.org/10.1097/01. brs.0000238657.13263.b2

20. Carricajo A, Nuti C, Aubert E, Hatem O, Fonsale N, Mallaval FO, Vautrin AC, Brunon J, Aubert G (2007) Propionibacterium acnes contamination in lumbar disc surgery. J Hosp Infect 66:275-277. https://doi.org/10.1016/j.jhin.2007.04.007

21. Rigal J, Thelen T, Byrne F, Cogniet A, Boissiere L, Aunoble S, Le Huec J-C (2016) Prospective study using anterior approach did not show association between Modic 1 changes and low grade infection in lumbar spine. Eur Spine J Off Publ Eur Spine Soc Eur Spinal Deform Soc Eur Sect Cerv Spine Res Soc 25:1000-1005

22. Tunney MM, Patrick S, Curran MD, Ramage G, Hanna D, Nixon JR, Gorman SP, Davis RI, Anderson N (1999) Detection of prosthetic hip infection at revision arthroplasty by immunofluorescence microscopy and PCR amplification of the bacterial 16S rRNA gene. J Clin Microbiol 37:3281-3290

23. Walters R, Moore R, Fraser R (2006) Penetration of cephazolin in human lumbar intervertebral disc. Spine (Phila Pa 1976) 31:567-570. https://doi.org/10.1097/01.brs.0000201244.24003.2d

24. Urban JPG, Roberts S, Ralphs JR (2000) The nucleus of the intervertebral disc from development to degeneration. Am Zool 40:53-61. https://doi.org/10.1093/icb/40.1.53

25. Marchand F, Ahmed AM (1990) Investigation of the laminate structure of lumbar disc anulus fibrosus. Spine (Phila Pa 1976) $15: 402-410$

26. Bratzler DW, Dellinger EP, Olsen KM, Perl TM, Auwaerter PG, Bolon MK, Fish DN, Napolitano LM, Sawyer RG, Slain D, Steinberg JP, Weinstein RA, American Society of Health-System P, Infectious Disease Society of A, Surgical Infection S, Society for Healthcare Epidemiology of A (2013) Clinical practice guidelines for antimicrobial prophylaxis in surgery. Am J Health Syst Pharm 70:195-283. https://doi.org/10.2146/ajhp120568

27. Shaffer WO, Baisden JL, Fernand R, Matz PG, North American Spine S (2013) An evidence-based clinical guideline for antibiotic prophylaxis in spine surgery. Spine J 13:1387-1392. https://doi. org/10.1016/j.spinee.2013.06.030

28. Das DB, Welling A, Urban JP, Boubriak OA (2009) Solute transport in intervertebral disc: experiments and finite element modeling. Ann N Y Acad Sci 1161:44-61. https://doi.org/10.111 1/j.1749-6632.2008.04075.x

29. Shah SR, Henslee AM, Spicer PP, Yokota S, Petrichenko S, Allahabadi S, Bennett GN, Wong ME, Kasper FK, Mikos AG (2014) Effects of antibiotic physicochemical properties on their release kinetics from biodegradable polymer microparticles. Pharm Res 31:3379-3389. https://doi.org/10.1007/s11095-014-1427-y

30. Capoor MN, Ruzicka F, Machackova T, Jancalek R, Smrcka M, Schmitz JE, Hermanova M, Sana J, Michu E, Baird JC, Ahmed FS, Maca K, Lipina R, Alamin TF, Coscia MF, Stonemetz JL, Witham T, Ehrlich GD, Gokaslan ZL, Mavrommatis K, Birkenmaier C,
Fischetti VA, Slaby O (2016) Prevalence of Propionibacterium acnes in intervertebral discs of patients undergoing lumbar microdiscectomy: a prospective cross-sectional study. PLoS One 11:e0161676. https://doi.org/10.1371/journal.pone.0161676

31. Albert HB, Kjaer P, Jensen TS, Sorensen JS, Bendix T, Manniche $\mathrm{C}$ (2008) Modic changes, possible causes and relation to low back pain. Med Hypotheses 70:361-368. https://doi.org/10.1016/j. mehy.2007.05.014

32. Zhu Q, Gao X, Li N, Gu W, Eismont F, Brown Mark D (2016) Kinetics of charged antibiotic penetration into human intervertebral discs: a numerical study. J Biomech 49:3079-3084

33. Tai CC, Want S, Quraishi NA, Batten J, Kalra M, Hughes SPF (2002) Antibiotic prophylaxis in surgery of the intervertebral disc. A comparison between gentamicin and cefuroxime. J Bone Joint Surg Br 84:1036-1039

34. Riley LH 3rd (1998) Prophylactic antibiotics for spine surgery: description of a regimen and its rationale. J South Orthop Assoc 7:212-217

35. Estes KS, Derendorf H (2010) Comparison of the pharmacokinetic properties of vancomycin, linezolid, tigecyclin, and daptomycin. Eur J Med Res 15:533-543

36. Komatsu M, Takahata M, Sugawara M, Takekuma Y, Kato T, Ito M, Abe Y, Irie T, Iwasaki N, Minami A (2010) Penetration of linezolid into rabbit intervertebral discs and surrounding tissues. Eur Spine J 19:2149-2155. https://doi.org/10.1007/s0058 6-010-1548-x

37. Boucher HW, Wilcox M, Talbot GH, Puttagunta S, Das AF, Dunne MW (2014) Once-weekly dalbavancin versus daily conventional therapy for skin infection. N Engl J Med 370:2169-2179. https:// doi.org/10.1056/NEJMoa1310480

38. Achermann Y, Goldstein EJ, Coenye T, Shirtliff ME (2014) Propionibacterium acnes: from commensal to opportunistic biofilmassociated implant pathogen. Clin Microbiol Rev 27:419-440. https://doi.org/10.1128/CMR.00092-13

39. Furustrand Tafin U, Corvec S, Betrisey B, Zimmerli W, Trampuz A (2012) Role of rifampin against Propionibacterium acnes biofilm in vitro and in an experimental foreign-body infection model. Antimicrob Agents Chemother 56:1885-1891. https://doi. org/10.1128/AAC.05552-11

40. Douglas A, Udy AA, Wallis SC, Jarrett P, Stuart J, Lassig-Smith M, Deans R, Roberts MS, Taraporewalla K, Jenkins J, Medley G, Lipman J, Roberts JA (2011) Plasma and tissue pharmacokinetics of cefazolin in patients undergoing elective and semielective abdominal aortic aneurysm open repair surgery. Antimicrob Agents Chemother 55:5238-5242. https://doi.org/10.1128/ AAC.05033-11

41. Smith RB, Phillips JP (1982) Evaluation of CLEOCIN HCl and CLEOCIN phosphate in an aged population. Upjohn TR 8147-82-9122-021

42. Cunha BA (2010) Pneumonia essentials. Physicians' Press, Sudbury, MA

\title{
Affiliations
}

\author{
Manu N. Capoor ${ }^{1,14}$ (] Jan Lochman ${ }^{2} \cdot$ Andrew McDowell $^{3}$. Jonathan E. Schmitz ${ }^{4}$. Martin Solansky ${ }^{2}$. \\ Martina Zapletalova ${ }^{2}$. Todd F. Alamin ${ }^{5}$. Michael F. Coscia ${ }^{6}$. Steven R. Garfin ${ }^{7}$ Radim Jancalek $^{8} \cdot$ Filip Ruzicka $^{9}$. \\ A. Nick Shamie ${ }^{10} \cdot$ Martin Smrcka $^{11}$. Jeffrey C. Wang ${ }^{12} \cdot$ Christof Birkenmaier $^{13}$. Ondrej Slaby ${ }^{14}$
}

Manu N. Capoor

mcapoor@mail.rockefeller.edu
Ondrej Slaby

ondrej.slaby@ceitec.muni.cz 
1 Laboratory of Bacterial Pathogenesis and Immunology, Rockefeller University, 1230 York Avenue, New York, NY, USA

2 Department of Biochemistry, Faculty of Science, Masaryk University, Brno, Czech Republic

3 Northern Ireland Centre for Stratified Medicine, School of Biomedical Sciences, Ulster University, Londonderry, UK

4 Department of Pathology, Microbiology and Immunology, Vanderbilt University School of Medicine, Nashville, TN, USA

5 Department of Orthopedic Surgery, Stanford University Medical Center, Stanford University, Stanford, CA, USA

6 Department of Orthopedic Surgery, OrthoIndy Hospital, Indianapolis, IN, USA

7 Department of Orthopaedic Surgery, University of California San Diego, San Diego, CA, USA

8 Department of Neurosurgery, Masaryk University, St. Anne's University Hospital, Brno, Czech Republic
9 Department of Microbiology, Masaryk University, St. Anne's University Hospital, Brno, Czech Republic

10 Department of Orthopaedic Surgery, David Geffen School of Medicine, University of California, Los Angeles, CA, USA

11 Department of Neurosurgery, University Hospital Brno, Masaryk University, Brno, Czech Republic

12 Department of Orthopedic Surgery, University Southern California, Los Angeles, CA, USA

13 Department of Orthopedics, Physical Medicine and Rehabilitation, University of Munich (LMU), Munich, Germany

14 Central European Institute of Technology (CEITEC), Masaryk University, Kamenice 753/5, 62500 Brno, Czech Republic 